\title{
Aeromechanics Analysis of a Distortion-Tolerant Fan with Boundary Layer Ingestion
}

\author{
Milind A. Bakhle \\ NASA Glenn Research Center, Cleveland, Ohio 44135, USA \\ T. S. R. Reddy \\ University of Toledo, Toledo, Ohio 43606, USA \\ Rula M. Coroneos, James B. Min, Andrew J. Provenza \\ NASA Glenn Research Center, Cleveland, Ohio 44135, USA \\ Kirsten P. Duffy \\ University of Toledo, Toledo, Ohio 43606, USA \\ George L. Stefko, Gregory S. Heinlein \\ NASA Glenn Research Center, Cleveland, Ohio 44135, USA
}

\begin{abstract}
A propulsion system with Boundary Layer Ingestion (BLI) has the potential to significantly reduce aircraft engine fuel burn. But a critical challenge is to design a fan that can operate continuously with a persistent BLI distortion without aeromechanical failure - flutter or high cycle fatigue due to forced response. High-fidelity computational aeromechanics analysis can be very valuable to support the design of a fan that has satisfactory aeromechanic characteristics and good aerodynamic performance and operability. Detailed aeromechanics analyses together with careful monitoring of the test article is necessary to avoid unexpected problems or failures during testing. In the present work, an aeromechanics analysis based on a three-dimensional, time-accurate, Reynolds-averaged Navier Stokes computational fluid dynamics code is used to study the performance and aeromechanical characteristics of the fan in both circumferentially-uniform and circumferentially-varying distorted flows. Pre-test aeromechanics analyses are used to prepare for the wind tunnel test and comparisons are made with measured blade vibration data after the test. The analysis shows that the fan has low levels of aerodynamic damping at various operating conditions examined. In the test, the fan remained free of flutter except at one near-stall operating condition. Analysis could not be performed at this low mass flow rate operating condition since it fell beyond the limit of numerical stability of the analysis code. The measured resonant forced response at a specific low-response crossing indicated that the analysis under-predicted this response and work is in progress to understand possible sources of differences and to analyze other larger resonant responses. Follow-on work is also planned with a coupled inlet-fan aeromechanics analysis that will more accurately represent the interactions between the fan and BLI distortion.
\end{abstract}

\section{Introduction}

$\mathrm{V}$ arious technologies are being pursued to reduce the fuel burn of commercial subsonic transport aircraft. Some aircraft engine technologies offer small incremental improvements but a few others offer a benefit large enough to be considered compelling for a future commercial aircraft application. One such technology is Boundary Layer Ingestion (BLI) propulsion, which has the potential for significant reduction in aircraft fuel burn ${ }^{1}$ that is achieved by ingesting and exhausting airflow at lower mean velocities, thus producing the required aircraft thrust with less propulsive power input or in other words improved propulsive efficiency. Other associated benefits include the elimination of some part of the nacelle and the entire pylon, which results in a decrease in weight and drag. Placement of the engines above the airframe can also result in a reduction of the noise reaching the ground due to shielding. Many system studies ${ }^{2-8}$ have been performed to quantify the fuel burn reduction with different assumptions and these 
studies have also identified the associated sensitivities and risks. High-performance, distortion-tolerant fan has been identified as a key technology required to achieve a significant BLI fuel burn benefit for future aircraft relative to a baseline high-performance, pylon-mounted, propulsion system. System-level benefits can be reduced or completely lost without a fan that can operate in a distorted flow due to boundary layer ingestion and still achieve high efficiency and adequate stall margin. Even more importantly, the fan must be structurally robust and meet the aeromechanical requirements regarding dynamic stresses and flutter stability to avoid structural failure. The fan in a BLI propulsion system must operate continuously in a distorted flow environment where it is subject to time-varying periodic aerodynamic excitations during each revolution resulting from the circumferential variation of flow properties and flow incidence on the blade due to boundary layer ingestion. This BLI operating environment is quite different from that for a typical wing-mounted engine fan that operates in clean undistorted flow except when there is cross-wind at take-off. The BLI distortion, in contrast, is always present during operation even at cruise conditions. Also, the severity of the BLI distortion can be comparable to the large distortion reaching the fan of a military aircraft engine during maneuver. The high frequency cyclic loading on the fan blades due to continuous flow distortion can lead to high dynamic stresses and fatigue failure of the fan blades. Flutter stability of the fan operating in BLI distortion is a concern.

This paper describes in detail the computational aeromechanics analysis performed on a Distortion-Tolerant Fan (DTF) designed to operate with a boundary layer ingesting inlet. This work was performed in advance of the experimental tests that were conducted in a high-speed wind tunnel to evaluate the performance and operability of the DTF fan with BLI ${ }^{9}$. The objectives of the aeromechanics analysis are to determine the flutter stability of the fan and to determine the resonant stresses in the fan blade due to operation in a BLI distortion. A companion paper will look at non-resonant forced response at design conditions and also other resonant responses at part-speed conditions.

\section{Fan Aerodynamic Analyses}

The aerodynamic analyses of the Distortion-Tolerant Fan (DTF) are described in this section. These unsteady aerodynamic analyses are critical to this work because they provide the unsteady forces on the fan blades that are used to determine both fan flutter stability and fan forced response. In the present work, only the fan rotor is modeled. The boundary layer ingesting (BLI) inlet is not included in the computations. Instead, the boundary layer flow distortion, extracted from a separate flow analysis, is prescribed as an inflow boundary condition upstream of the rotor ${ }^{10}$. In future work, the approximation error introduced in this decoupled approach will be evaluated by comparison with a coupled inlet-fan analysis ${ }^{11}$ that computes the flowfield in both the inlet and the fan simultaneously. In the current analyses, it is assumed that the first order effects of the strong BLI distortion are captured adequately using the selected approach.

A time-domain unsteady Reynolds-averaged Navier Stokes solver is used to model the unsteady flowfield resulting from the BLI distortion and fan blade vibrations. The TURBO unsteady aerodynamic analysis code, described in Refs. 12 and 13, is an implicit finite-volume code that uses structured multi-block grids to model fan flow. Previous applications of TURBO in the study of flutter and forced vibration are presented in Refs. 14-16. An inlet distortion boundary condition is used at the upstream boundary to prescribe the flow. With this inlet distortion boundary condition, a specified distribution of total conditions is held as described in Ref. 17. A throttle exit boundary condition is used at the downstream boundary to avoid over-constraining the exit flow; this boundary condition maintains only the integrated corrected mass flow through the exit plane at a prescribed value, while local flow quantities are free to attain local equilibrium. For fan aeromechanics analysis with blade vibrations, dynamic grid deformation is used to prescribe harmonic blade vibrations and the energy method is used to evaluate aerodynamic damping and flutter stability.

In this study of the BLI fan, an $\mathrm{O}$ mesh wraps around each blade in the chordwise direction and $\mathrm{H}$ meshes are used in the blade passages and in the tip gap between the blade and the casing. Figure 1 shows azimuthal and radial views of the meshes for a blade passage. The placement of the upstream inflow boundary was constrained in part by the requirement to model only an axisymmetric geometry. The inlet located upstream of the fan rotor has a non-axisymmetric shape and is therefore excluded from the fan rotor domain. On the downstream side, since the spacing between the fan rotor and the exit guide vanes is fairly large, and since the exit guide vanes are not modeled in this analysis, the outflow boundary was located significantly downstream of the fan trailing edge. The flow path was modified slightly from the actual design to maintain an axisymmetric geometry and facilitate the placement of the outflow boundary farther from the fan rotor. 

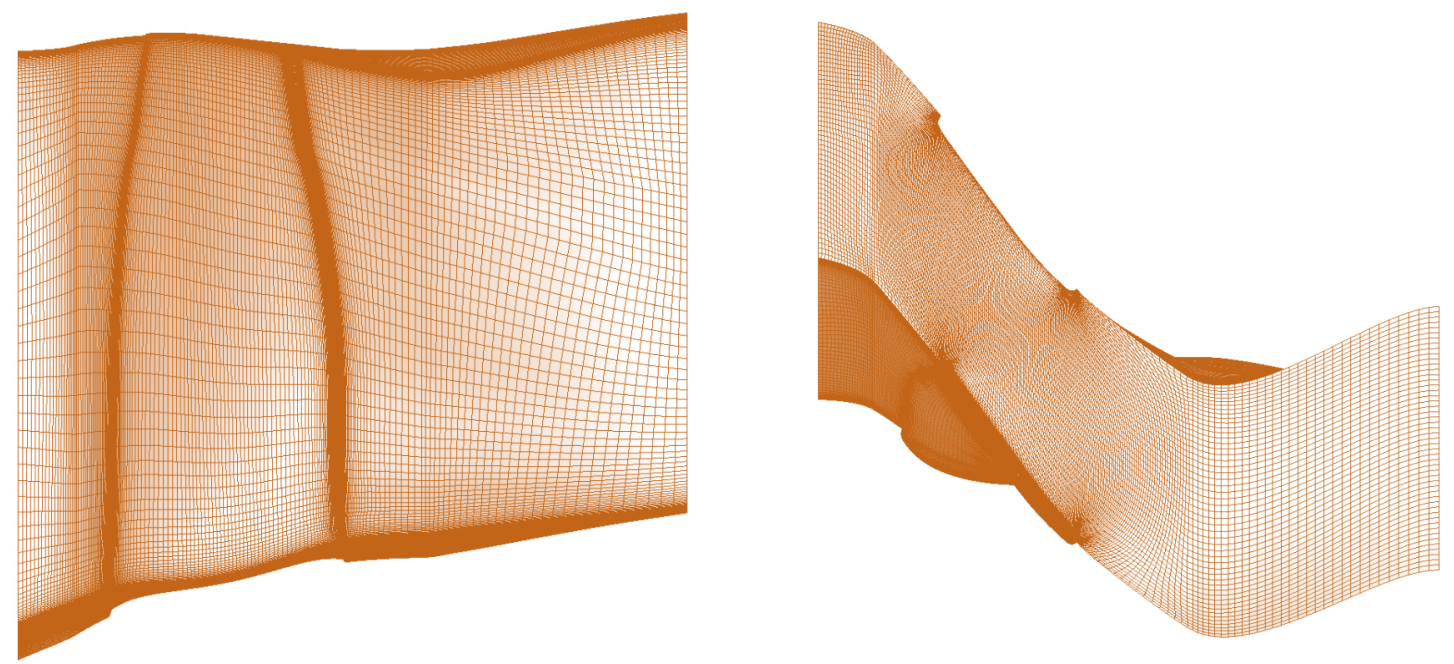

Figure 1. Azimuthal and radial views of computational meshes for one blade passage.

As a baseline, aerodynamic analyses done with a circumferentially-averaged flow profile prescribed at the inflow boundary. Only radial variations of total pressure, total temperature, tangential flow angle, and radial flow angle are present at the inflow plane as shown in Fig. 2. These variations are obtained by taking the circumferential average of the BLI distortion that is described later in the paper. Although there is no variation of flow properties in the circumferential or azimuthal direction, these circumferentially-averaged profiles are somewhat different from typical clean inflow profiles. For example, an engine in a typical under-wing mount would experience clean inflow if there is no crosswind or sideslip present. For such a fan operating without boundary layer ingestion, a typical clean inflow profile would have only a small variation in the total pressure near the hub and casing due to relatively thin boundary layers. In this part of the work, we have used the circumferential average of the BLI distortion to obtain the inflow profiles so as to provide some common basis for comparison with the circumferentially- and radially-varying full BLI distortion inflow results to follow.

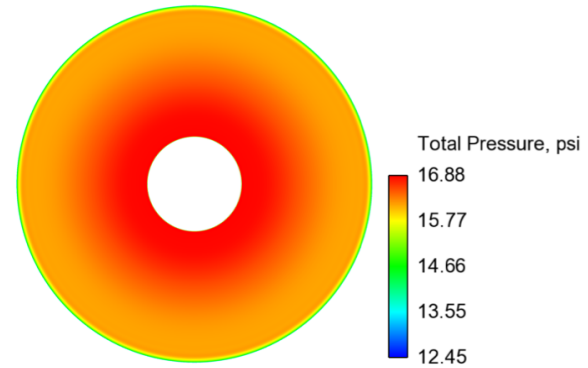

a) total pressure

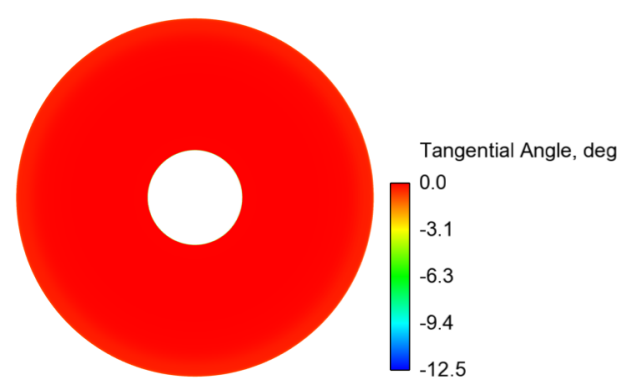

c) circumferential flow angle

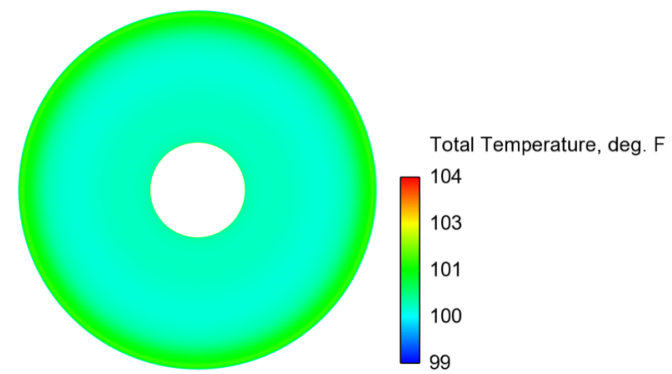

b) total temperature

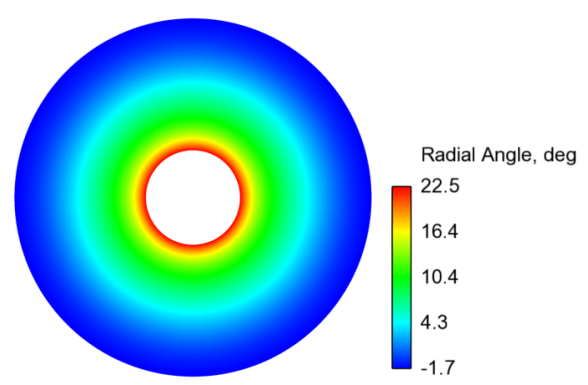

d) radial flow angle

Figure 2. Flow variables at the inflow plane for circumferentially-averaged inflow analyses. 
For this circumferentially-averaged inflow condition, analysis is performed in one blade passage with periodic boundary conditions applied in the azimuthal direction. Analyses are done at fixed rotational speed and the mass flow rate is set using the exit throttle boundary condition. A converged solution is obtained for a prescribed exit boundary condition and a speed line is obtained by changing the exit boundary condition parameter, keeping the rotational speed fixed. Analyses are repeated at three rotational speeds: $100 \%$ (design) speed, $85 \%$ speed, and $70 \%$ speed. Figure 3 shows the performance characteristics of the fan: rotor total pressure ratio and rotor adiabatic efficiency versus inlet corrected mass flow rate. All results shown are from fully converged flow solutions. No converged solutions were obtained at lower mass flow rates and no attempt was made to reduce the step in the exit throttle boundary condition parameter to locate a numerical stability boundary more accurately. The performance characteristics with circumferentially-averaged inflow serve as a baseline for computations with the full circumferentially- and radiallyvarying BLI distortion inflow that follow.

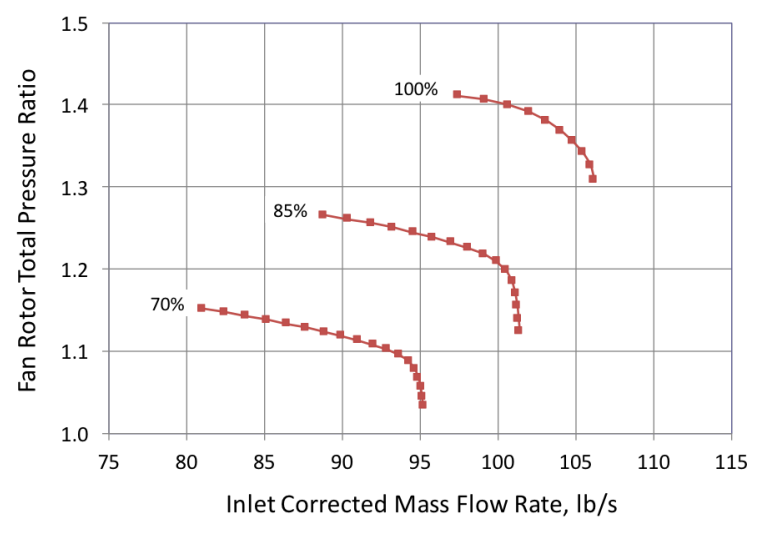

a) total pressure ratio

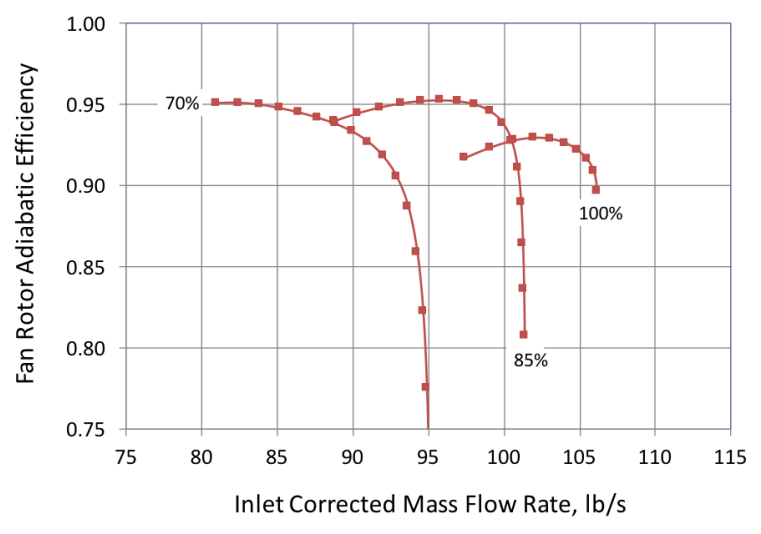

b) adiabatic efficiency

Figure 3. Performance characteristics of fan with circumferentially-averaged inflow. 
Following the analyses with circumferentially-averaged inflow, analyses were performed with the boundary layer ingestion (BLI) distortion inflow profile, which has flow quantities that vary in both the circumferential and radial directions. The relevant flow quantities required to fully prescribe the inlet boundary condition are shown in Fig. 4. Note that the distortion shown is for the design condition. The distortion patterns varied with operating conditions and rotational speed.

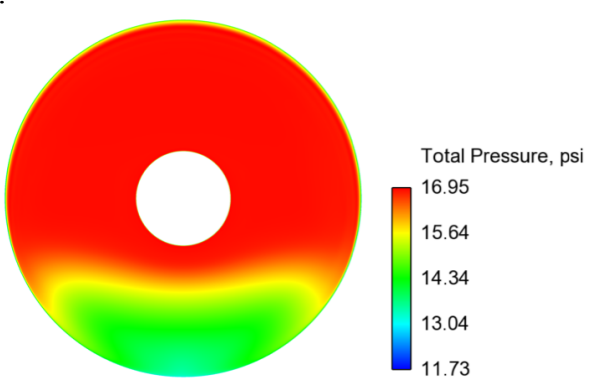

a) total pressure

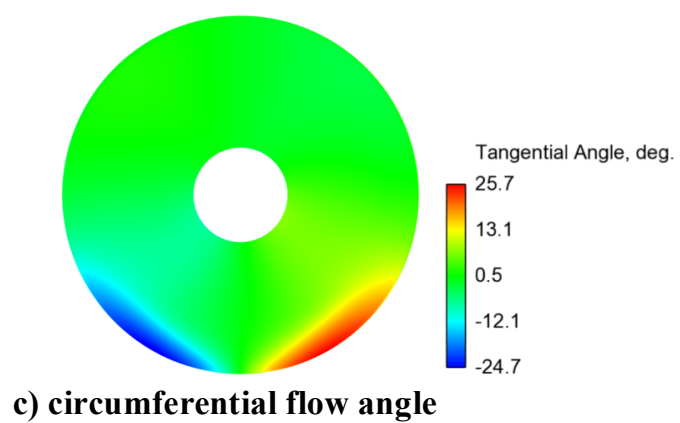

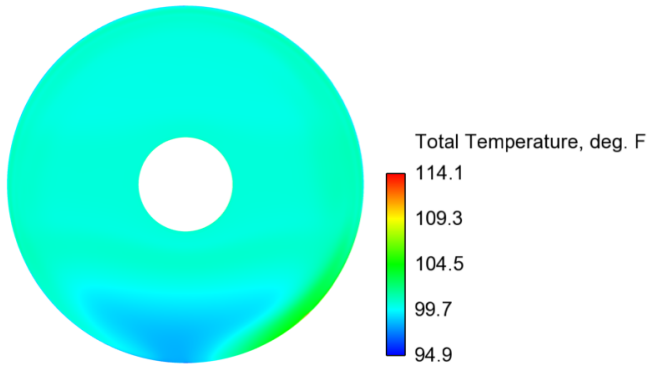

b) total temperature

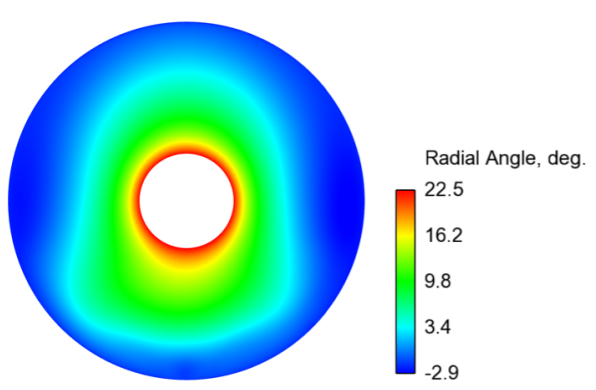

d) radial flow angle

Figure 4. Flow variables at the inflow plane for BLI distortion analyses.

For this computation, all 18 blade passages of the 18-blade fan rotor are included. The time-accurate unsteady computations are advanced with 100 time steps per passage, or 1800 time steps per rotor revolution. The solutions were typically run for 6 to 9 revolutions to allow the flowfield to become periodic. The typical time histories of inlet corrected mass flow rate are shown in Fig. 5 for $100 \%, 85 \%$, and $70 \%$ rotational speeds and various exit throttle boundary condition settings. Legends are not included in Fig. 5 since the intent is to show the levels of unsteadiness in the solutions, as well as the large variation in convergence rates. For the lower mass flow rates at $100 \%$ speed, the convergence is slow compared to the high mass flow rates on the choke side. Unsteadiness in the flow field results from different blade passages passing through the low total pressure zones of the BLI distortion where the fan blades stall and subsequently recover when they reach the higher total pressure regions. In addition, the exit throttle boundary condition also may cause unsteadiness as it adjusts to maintain a target mass flow rate. Flow field variations are present between passages at the same location at different times. At the $85 \%$ and $70 \%$ rotational speeds, the higher mass flow rate conditions also show considerable unsteadiness at high frequency.

Another way to illustrate the unsteadiness in the flow at various operating conditions is by plotting the instantaneous values of corrected mass flow rate and pressure ratio at each time step during the last revolution. Figure 6 shows the fan map with the BLI distortion. At each combination of rotational speed and exit throttle condition, 1800 individual results for mass flow rate and pressure ratio are plotted from the last revolution of the fan. If there was no unsteadiness, all 1800 results would be plotted at the exact same location and would appear as one symbol. With the unsteadiness in the flow, the scatter in the plotted results shows the range of variation in mass flow rate and pressure ratio. And, the scatter of the results also clearly shows the relative levels of unsteadiness at various operating conditions on the fan map.

Next, a comparison of the performance results in circumferentially-averaged inflow and with the complete BLI distortion is shown in Fig. 7. In this plot, the unsteady results with the BLI distortion are averaged over the last revolution. The plot shows, as expected, a decrease in total pressure ratio due to the BLI distortion as compared to the circumferentially-averaged inflow. 


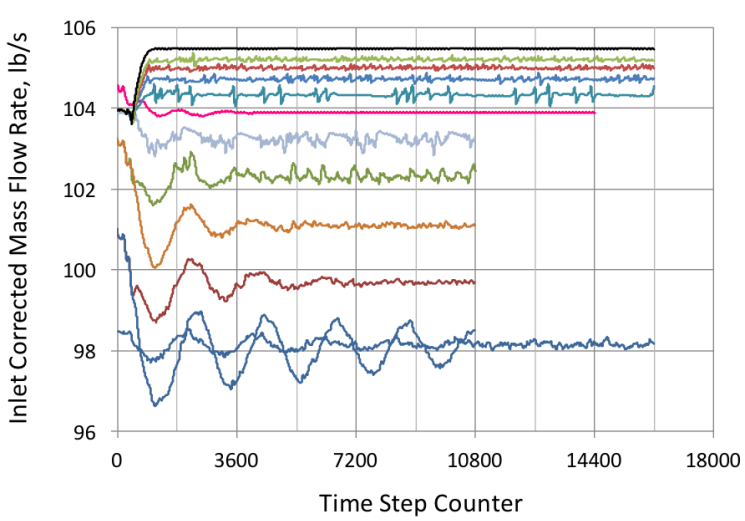

a) $\mathbf{1 0 0} \%$ rotational speed

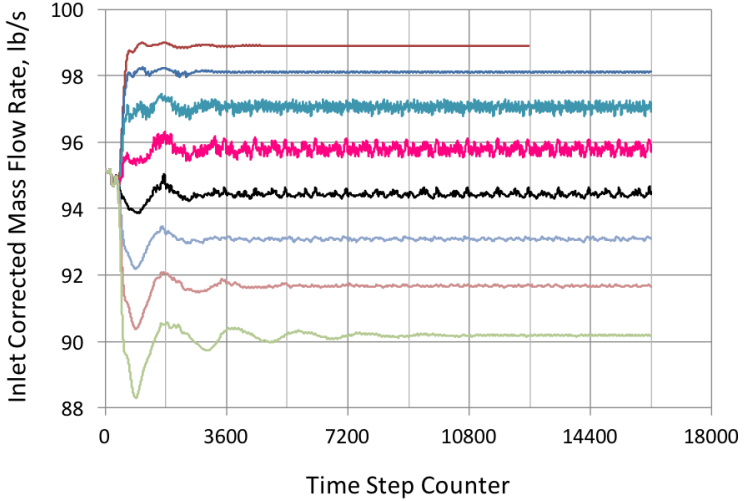

b) $85 \%$ rotational speed

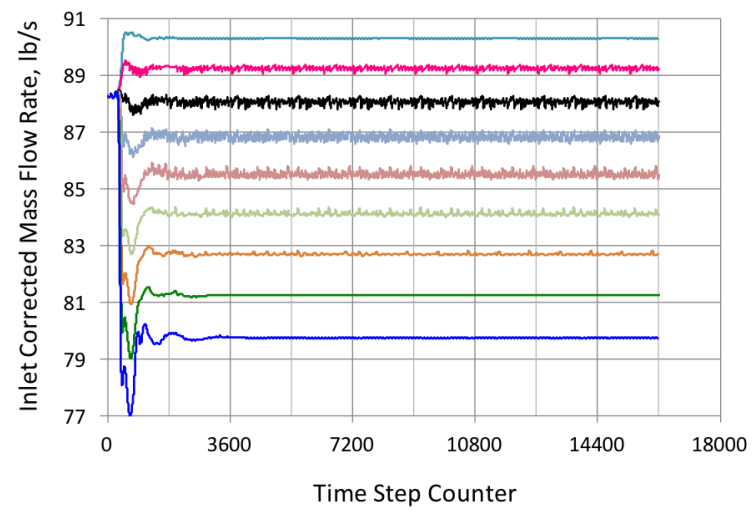

c) $70 \%$ rotational speed

Figure 5. Time history of inlet corrected mass flow rate with BLI distortion.

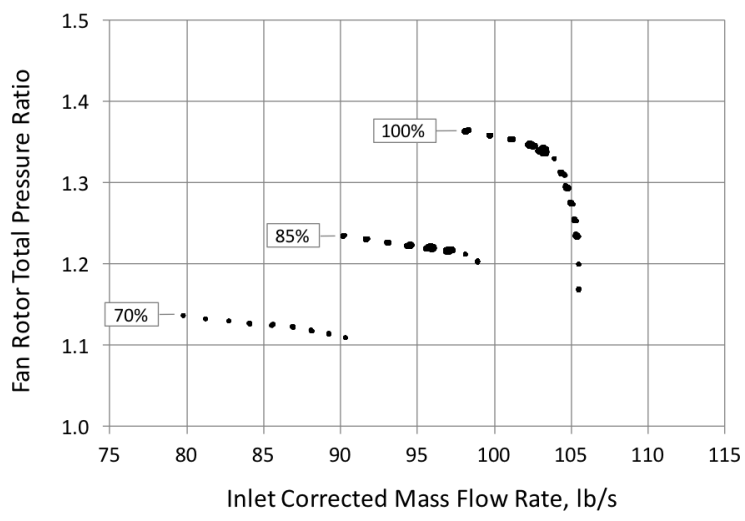

Figure 6. Fan map with BLI distortion showing unsteadiness during the last revolution.

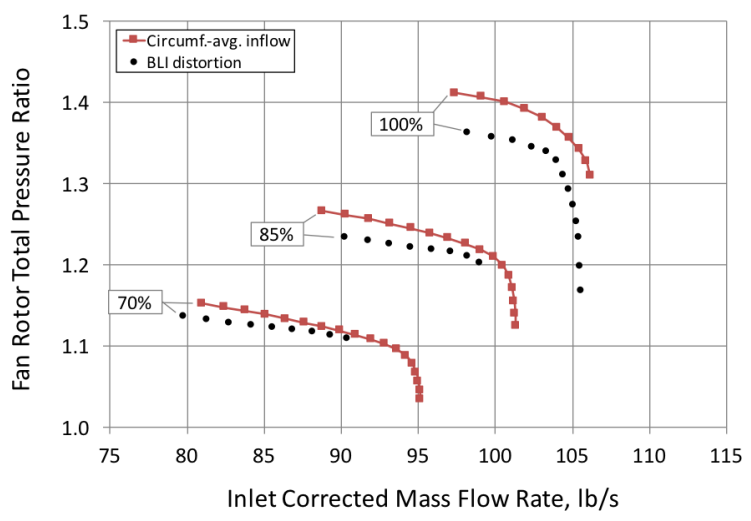

Figure 7. Comparison of fan performance with circumferentially-averaged inflow and BLI distortion. 


\section{Fan Blade Structural Analysis}

\section{A. Finite Element Model}

A structural finite element model for the fan blade and disk assembly is developed from a CAD (Computer-Aided Design) model available as a STEP (Standard for the Exchange of Product model data) file. The structural model developed for the design geometry includes the fan blade airfoil, platform, dovetail attachment, and a sector of the disk. Commercial software MSC Patran is used for meshing, analysis setup, pre-processing and post-processing; commercial software MSC Nastran is used for structural analysis. Cyclic symmetry analysis is used and thus the model includes a $1 / 18^{\text {th }}$ sector of the disk and one fan blade of 18 total as shown in Fig. 8. The blade is directly connected to the disk using Multi Point Constraint (MPC) and Rigid Body Element (RBE2) entries. Due to the large centrifugal forces on the rotating blade, it is expected that the blade dovetail will remain in direct contact with the dovetail slot in the disk during typical operating conditions. Boundary conditions are applied at the inner radius of the disk sector to restrain motion in the radial and circumferential directions. The blade is modeled with 8-node hexahedral (CHEXA) elements and the disk sector is modeled using 20-node CHEXA elements. The cyclic symmetry model includes 25,102 nodes and 9,282 elements. The blade is modeled with material properties for titanium alloy Ti-6Al-4V and the disk is modeled with material properties for 17-4 stainless steel.

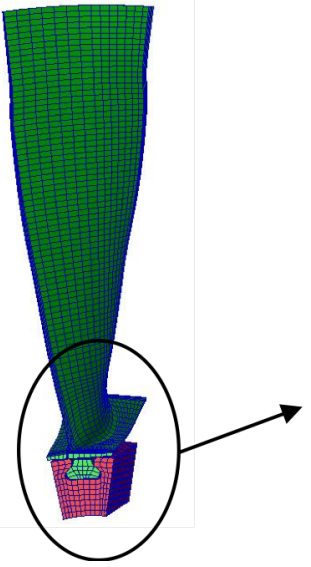

a) one blade and $1 / 18^{\text {th }}$ disk sector

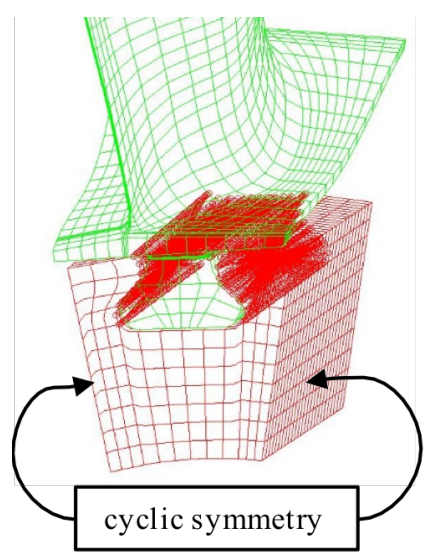

b) connections between blade and disk

Figure 8. Fan blade cyclic symmetry structural model.

\section{B. Structural Analysis}

The model described in the preceding section is used with MSC Nastran software to perform cyclic symmetry structural analysis. Since the as-designed blade geometry in the CAD model is provided at design operating speed (deflected or deformed hot shape), only linear analyses are performed. Static and modal analyses are performed to calculate blade static stresses and modal frequencies, modal displacements (mode shapes), and modal stresses. The analyses include the effects of centrifugal stiffening and softening. Steady aerodynamic loading is not included in the modal analysis since previous studies have shown that steady aerodynamic loading has only a minimal effect on the modal frequency and mode shape results.

Since the structural model includes a disk sector and a blade, distinct modal results are obtained for each nodal diameter (ND) pattern for each mode family. The nodal diameter pattern is sometimes also identified by a harmonic index. For the DTF fan with 18 blades, the number of nodal diameters can vary from 0 to 9 . The cyclic symmetry modal analysis can be performed separately for each nodal diameter pattern or harmonic index. The modal displacement results are obtained as sine and cosine wave forms that vary around the disk in the prescribed nodal diameter or harmonic pattern. For example, for the 1 nodal diameter pattern, the displacement contains one diametral node line where the displacement goes to zero at two azimuthal (circumferential) locations. Figure 9 shows the modal displacements for the mode 1 family for the 1 and 2 nodal diameter patterns. No contour levels are included since the intent is to show the vibration mode shape pattern around the rotor including the nodal diameters. 


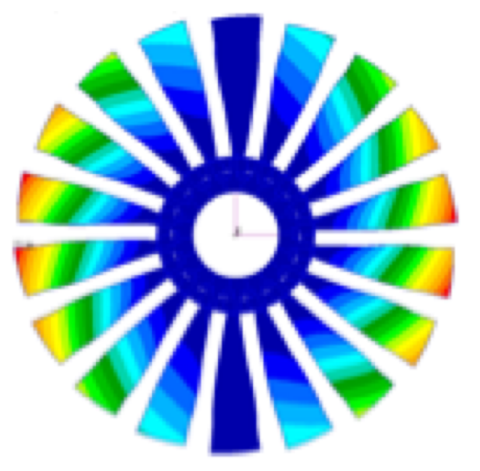

a) 1 nodal diameter (1 ND) pattern

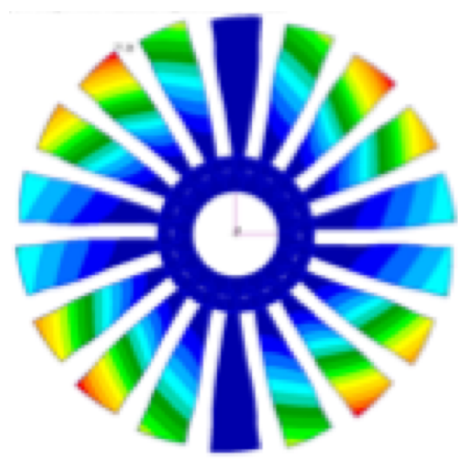

b) 2 nodal diameter (2 ND) pattern

Figure 9. Fan blade cyclic symmetry modal displacements (mode shapes) for mode 1.

The calculated blade natural frequencies were compared to measurements from the wind tunnel test. Table 1 shows the comparison of frequencies near the design speed for several modes and relevant nodal diameter patterns. The actual physical speed corresponding to the measurements was used in these analyses. The close agreement between the predicted and measured frequencies provides some verification that the structural dynamics characteristics are modeled well using the blade-disk model and the cyclic symmetry analysis.

Table 1. Calculated and measured blade frequencies for DTF fan.

\begin{tabular}{cccccc}
\hline Mode & $\begin{array}{c}\text { Nodal } \\
\text { diameter } \\
\text { pattern }\end{array}$ & $\begin{array}{c}\text { Calculated Measured Difference Difference } \\
\text { frequency } \\
(\mathrm{Hz})\end{array}$ & $\begin{array}{c}\text { frequency } \\
(\mathrm{Hz})\end{array}$ & $\begin{array}{c}\text { (Hz) } \\
\%\end{array}$ \\
\hline 1 & 1 & 269 & 268 & 1 & $0.5 \%$ \\
\hline 2 & 3 & 712 & 714 & -2 & $-0.3 \%$ \\
\hline 3 & 5 & 1019 & 1004 & 15 & $1.5 \%$ \\
\hline 4 & 7 & 1438 & 1462 & -24 & $-1.6 \%$ \\
\hline 5 & 8 & 1971 & 2008 & -37 & $-1.8 \%$ \\
\hline 6 & 7 & 2298 & 2310 & -12 & $-0.5 \%$ \\
\hline 7 & 5 & 2696 & 2705 & -9 & $-0.3 \%$ \\
\hline 8 & 3 & 3036 & 3013 & 36 & $0.8 \%$ \\
\hline
\end{tabular}

\section{Fan Blade Flutter Stability}

Fan flutter stability is evaluated using the energy method, or work-per-cycle method, described in Refs. 18 and 19. The structural mode shape is used to prescribe a harmonic vibration for each blade at the natural frequency. In the TURBO analysis code, blade vibrations are prescribed through dynamic grid deformation. The maximum modal displacements from the finite element analysis results are interpolated or mapped from the structural finite element blade mesh on to the TURBO blade surface mesh and then smoothly propagated away from the blade surface into the rest of the computational domain. The nodal diameter pattern from the finite element analysis is used to prescribe traveling wave displacements for each blade in TURBO with a fixed inter-blade phase angle between adjacent blades. The cyclic symmetry finite element analysis results are in the form of sine and cosine components but only the maximum displacements on a blade are needed and used in TURBO since the traveling wave displacements for all the blades can be prescribed using the maximum displacements and the inter-blade phase angle. Thus, the same formulation used in previous work ${ }^{19}$ for a blade-alone structural analysis is also used here for blade-disk structural analysis. In the flutter calculations with the TURBO code, an arbitrary scale factor or amplitude is applied on the blade 
vibrations to uniformly scale down the mode shape since we are primarily interested in the onset of flutter where the blade vibrations are very small. This scaling also helps to avoid any numerical difficulties related to large grid deformations.

First, analysis is done with a circumferentially-averaged inflow, which comprises only radial variations of flow quantities at the inflow boundary. The initial transients related to the start of the harmonic vibration decay after a few cycles and the flowfield is seen to reach periodicity as assessed by the convergence of the work per cycle on all blades. The aerodynamic damping, calculated from the work per cycle, provides a measure of flutter stability. The fan can flutter at the operating condition being analyzed if the aerodynamic damping is negative for any of the nodal diameter patterns for any mode. All the different nodal diameter patterns need to be analyzed individually with both forward and backward traveling waves with respect to the direction of rotation, represented as positive and negative nodal diameter indices respectively. For each mode of interest, the total number of analyses is thus equal to the number of blades on the fan rotor (18) since the $\pm 9 \mathrm{ND}$ (nodal diameter) cases are both the same and there is no travel direction for the 0 ND case.

The total system damping is composed of aerodynamic damping and structural damping (material and mechanical damping). For metal blades, material damping is extremely small and the mechanical damping is also expected to be fairly small since no damper device is included in this fan design. Some structural damping will likely be present due to friction at the dovetail between the blades and the disk or between adjacent platforms. The amount of structural damping can vary with vibration mode, amplitude, and frequency. For a conservative assessment of flutter stability, structural damping is not considered in the present work.

\section{A. Circumferentially-Averaged Inflow}

Fan flutter calculations are performed for mode 1 (bending) at the design rotational speed. The blade vibration mode shape and frequency specific to a selected nodal diameter pattern are used in each flutter calculation. For mode 1 , there is no significant change in the mode shape and frequency with the nodal diameter ${ }^{20}$. As the nodal diameter pattern changes, a comparison of the blades with the largest displacements indicates that the mode shapes remain very nearly the same as illustrated in Fig. 10 for selected nodal diameter patterns. In the aerodynamic damping calculations, the computational domain consisted of all 18 blade passages (full rotor analysis) for all nodal diameter patterns analyzed. The aerodynamic damping converged to the average value within a few vibration cycles; most cases are run for 10 cycles of vibration. The aerodynamic damping calculated at the nominal operating point for various nodal diameter patterns is shown in Fig. 11. There is a large variation of aerodynamic damping with nodal diameter pattern with a high value near $9 \%$ for the $\pm 9 \mathrm{ND}$ (nodal diameter) pattern and a low value of $0.6 \%$ for the $0 \mathrm{ND}$ pattern. Decreasing mass flow rate along the speed line increases incidence on the blades and moves the operating condition towards stall and can sometimes result in a drop in aerodynamic damping and possibly flutter. Additional analyses are performed for a few selected nodal diameter patterns at the design rotational speed for a low mass flow rate below the nominal operating point. This condition, which is near the numerical stability limit for the TURBO code, is denoted as near stall since it is expected to be represent the low mass flow rate and high-incidence conditions near the stall line of the fan. The results, shown in Fig. 12, indicate that for the near stall condition, the minimum aerodynamic damping value remains approximately the same but the minimum occurs for the 1 ND pattern instead of the 0 ND pattern. Further, the lowest calculated aerodynamic damping values are small but positive, not indicating flutter for mode 1 vibrations with circumferentially-averaged inflow.

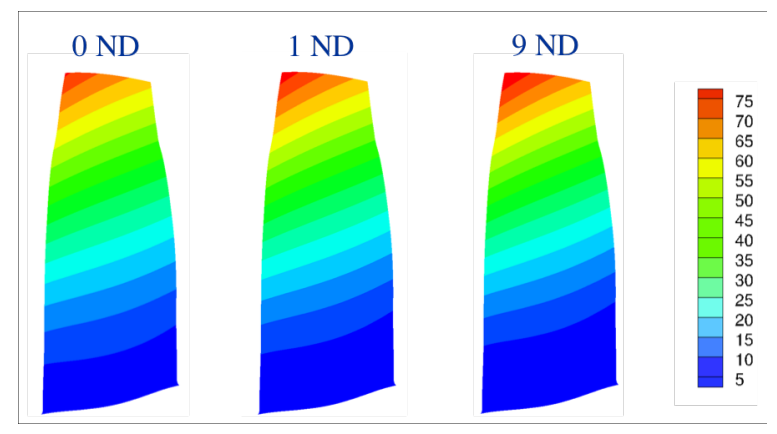

Figure 10. Mode 1 mode shapes for different nodal diameter (ND) patterns. 


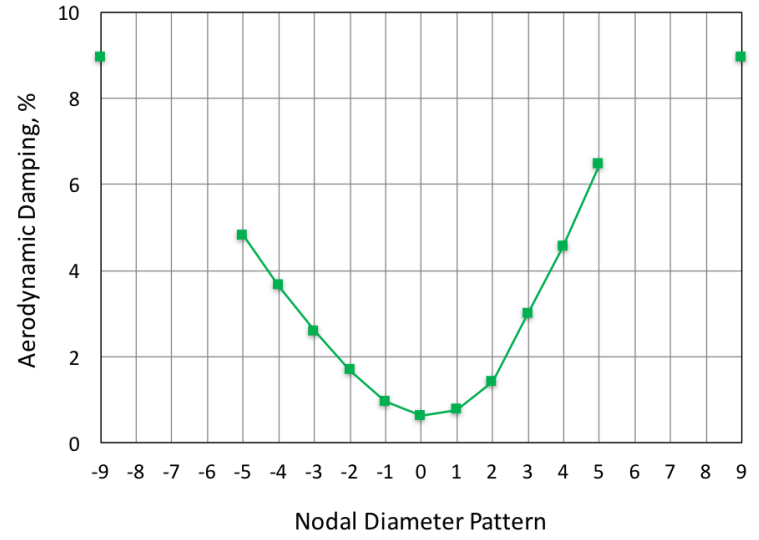

Figure 11. Mode 1 aerodynamic damping for circumferentially-averaged inflow at design rotational speed, nominal operating point.

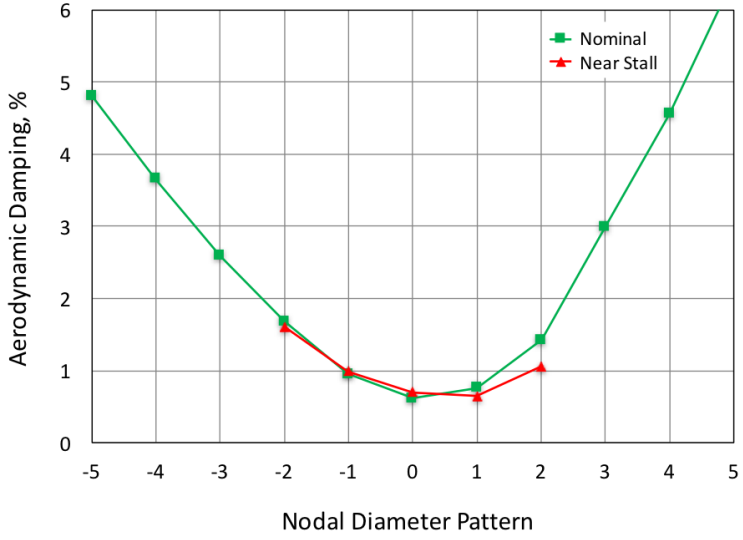

Figure 12. Mode 1 aerodynamic damping variation for circumferentially-averaged inflow at design rotational speed.

For mode 2, flutter calculations are performed at the design rotational speed as described previously for mode 1. As noted for mode 1, the blade vibration mode shape and frequency specific to a selected nodal diameter pattern are used in each flutter calculation. For mode 2, the aerodynamic damping calculated at the nominal operating point for various nodal diameter patterns is shown in Fig. 13. The range of values of the calculated aerodynamic damping is from $1.23 \%$ for the \pm 9 ND patterns to $0.15 \%$ for the 1 ND pattern. For the near stall operating point, the aerodynamic damping for the 1 ND pattern drops to $0.09 \%$. Figure 14 shows that there is a significant change in the mode shape for mode 2 with the nodal diameter pattern. The changes in mode shape and frequency with nodal diameter pattern are a result of the blade-disk dynamics captured by the structural model that includes the blade airfoil, platform, dovetail attachment and disk sector modeled with cyclic symmetry boundary conditions ${ }^{20}$. Note the differences in the shapes of the contour lines as well as the range of values particularly for the 1 ND pattern. The calculated aerodynamic damping at \pm 1 ND clearly reflects this difference in mode shape.

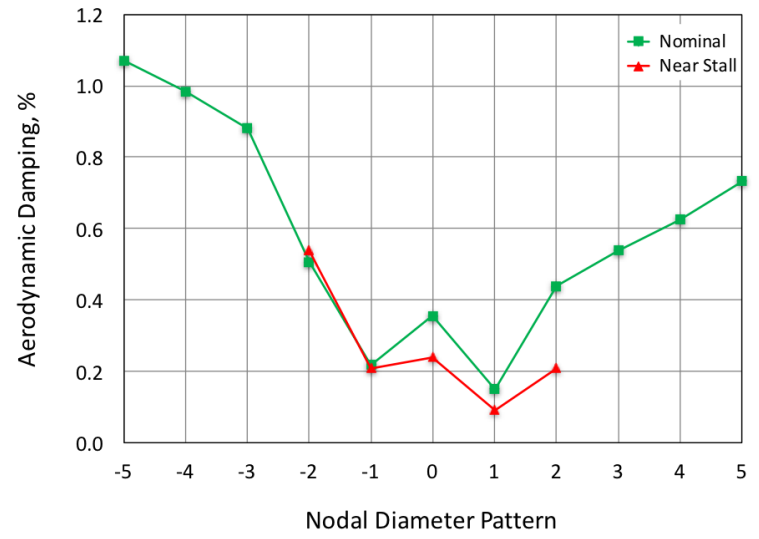

Figure 13. Mode 2 aerodynamic damping variation for circumferentially-averaged inflow at design rotational speed.

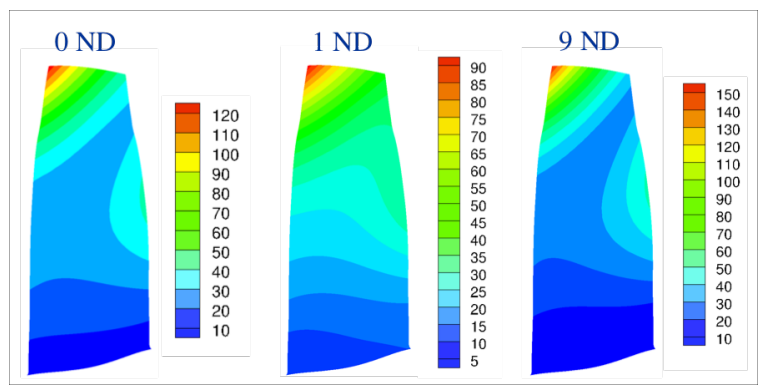

Figure 14. Mode 2 mode shapes for different nodal diameter (ND) patterns.

For mode 3, the aerodynamic damping calculated at the nominal operating point is shown in Fig. 15. The range of values of the calculated aerodynamic damping is from $1.79 \%$ for the \pm 9 ND patterns to $0.48 \%$ for the 1 ND pattern. For the near stall operating point, the aerodynamic damping for the $1 \mathrm{ND}$ pattern drops to $0.34 \%$. The mode shape patterns for mode 3 also show a very significant variation with nodal diameter pattern as shown in Fig. 16. The location and shape of the node line shows large variations across the nodal diameter range and is reflected in the variations in 
calculated aerodynamic damping. It is noted that for this mode, the location of the highest deflection changes from the leading edge to the trailing edge.

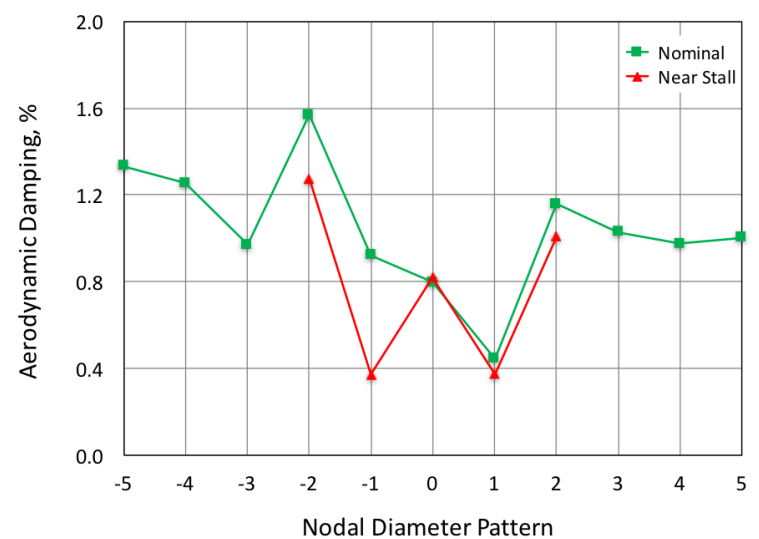

Figure 15. Mode 3 aerodynamic damping variation for circumferentially-averaged inflow at design rotational speed.

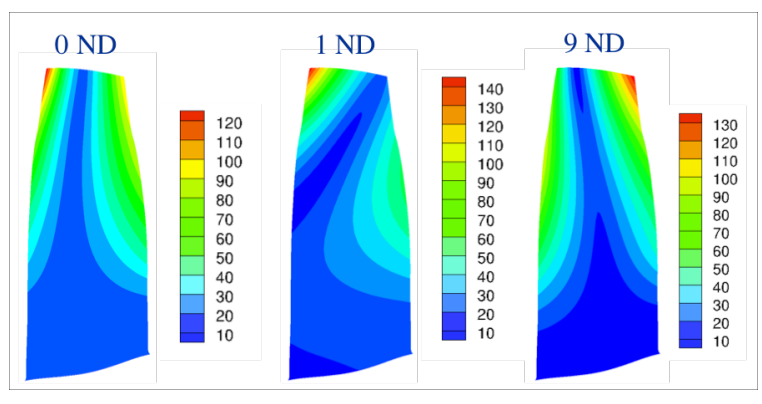

Figure 16. Mode 3 mode shapes for different nodal diameter (ND) patterns.

To check the effects of the time step used in the computations on the aerodynamic damping result, the time step was reduced in half with only a minimal effect on the aerodynamic damping in the second decimal place of the percentage value for mode 2, 1 ND pattern. Similarly, when the amplitude of vibration was increased or decreased by a factor of two, the aerodynamic damping value changed only minimally in the second decimal place of the percentage value.

\section{B. Distorted Inflow}

For the DTF fan operating with a BLI distorted inflow, the flow over each blade changes as it rotates through the distorted flowfield. This results in an unsteady pressure loading on each blade, which acts as an external forcing on the blade. In addition, if a blade vibrates, it also produces unsteadiness in the flow, which also results in an unsteady pressure loading on the blade. For flutter stability, the latter unsteadiness related to blade vibration is of interest. Since both sources of unsteadiness are present simultaneously, distorted inflow and blade vibrations are prescribed simultaneously in the computational analysis ${ }^{10}$. The work-per-cycle computation is modified to subtract out the effects of unsteady pressure due to distorted inflow on non-vibrating blades. This approach requires two computations with distorted inflow: one with vibrating blades and the other with non-vibrating blades. The difference between the calculated work-per-cycle is attributed to the effect of blade vibrations and thus related to flutter stability. Since the fan blade rotational frequency is typically not an integral multiple of the blade vibration frequency, each blade vibration cycle takes place in a different flowfield depending on the location of the blades relative to the BLI inlet distortion. Hence, each vibration cycle of each fan blade will be different, and thus the work-per-cycle will not converge to a single value for all blades even after multiple vibration cycles as it does for circumferentially-averaged inflow. Instead, the results of the computations represent a range of aerodynamic damping values.

The analysis described in the preceding paragraph is performed for all three modes for various nodal diameter patterns. To illustrate the characteristics of the aerodynamic damping variations, results are presented for the design rotational speed at the nominal operating point. Figure 17 shows the aerodynamic damping after each cycle of vibration for all 18 blades for mode 1 vibrations in the 1 ND (nodal diameter) pattern. Recall that for the circumferentially-averaged inflow analysis, the $1 \mathrm{ND}$ pattern showed the lowest aerodynamic damping. The results for cycles 1 and 2 are not plotted because the large startup transient effects led to large scatter in the results for this case. The average value for 18 blades is also shown for each vibration cycle. It is noted that all the calculated aerodynamic damping values are positive indicating no flutter for this operating condition. The scatter in the results indicates the effect of the BLI distortion on the calculated work-per-cycle of individual blades. Since each blade starts and ends each vibration cycle at a different location, the work done on the blade by the unsteady pressure forces is different for each blade and for each vibration cycle. Due to the low vibration frequency of the first mode, a large amount of computational time is required for each vibration cycle and only 10 cycles were run for this case. Figure 
18 shows the same aerodynamic damping results plotted for each blade. The first two vibration cycles are not included in the calculation of the average aerodynamic damping, which is seen to be over $0.5 \%$ for all the blades. It is expected that if more cycles are run, the variation in results for different blades will decrease.

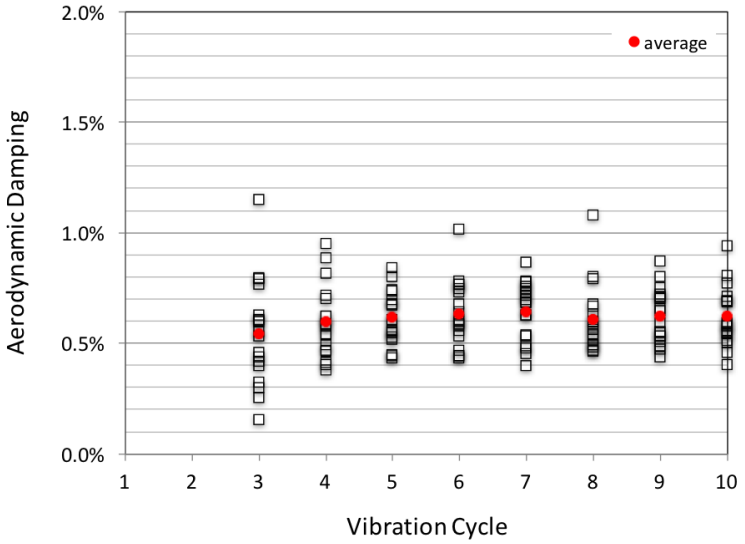

Figure 17. Mode 1, 1 ND aerodynamic damping with BLI distorted inflow.

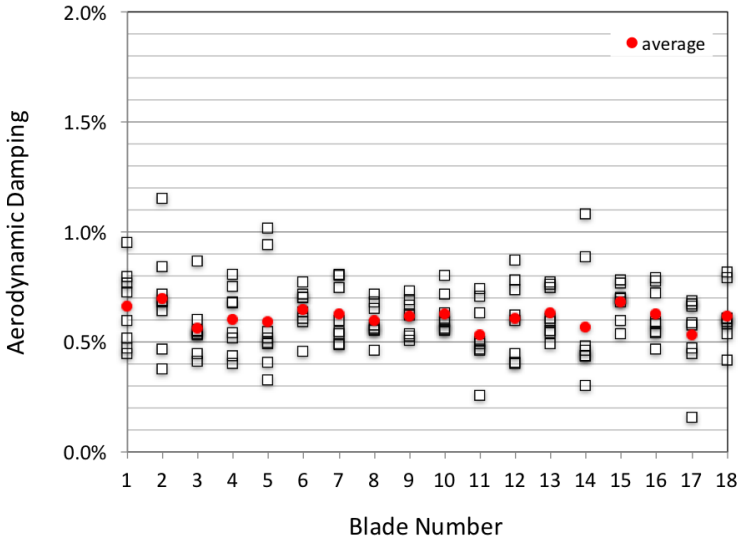

Figure 18. Mode 1, 1 ND aerodynamic damping with distorted inflow for each blade.

Figures 19 and 20 show the mode 2 aerodynamic damping for the 1 nodal diameter pattern with distorted inflow. The results for cycles 1-4 are not included because of the large scatter in results due to transients. As compared to the first mode, the second mode frequency is higher and that allows computations for a larger number of vibration cycles to be done for the same time step. In this case, a total of 25 vibration cycles were computed. For mode 2, all the aerodynamic damping results are positive indicating no flutter at this condition. The average value is fairly low, approximately $0.2 \%$ with most of the values falling in a narrow band between $0.15 \%$ and $0.25 \%$. The scatter in results is small as compared to the mode 1 results.

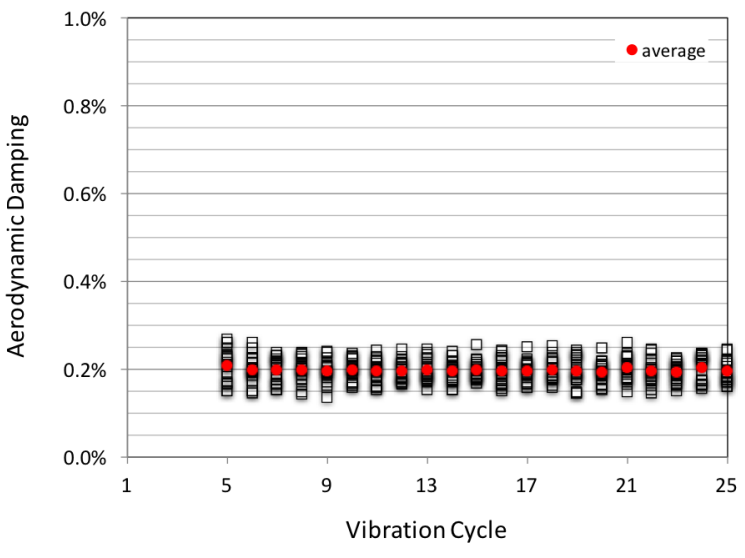

Figure 19. Mode 2, 1 ND aerodynamic damping with BLI distorted inflow.

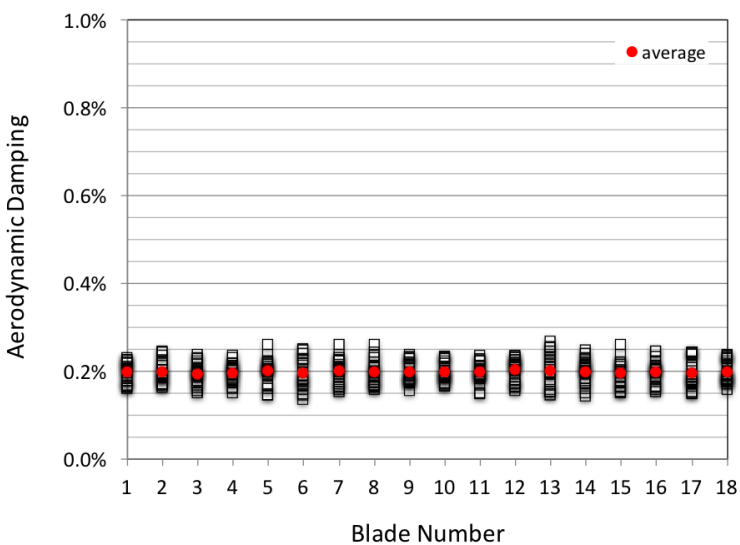

Figure 20. Mode 2, 1 ND aerodynamic damping with BLI distorted inflow for each blade.

Figures 21 and 22 show the mode 3 aerodynamic damping for the 1 ND pattern with distorted inflow. A total of 21 vibration cycles were computed for this case. The results for cycles 1-5 are not included because of the large scatter in results due to transients. For mode3, all the aerodynamic damping results are positive indicating no flutter at this condition. The average aerodynamic damping value for mode 3 is approximately $0.5 \%$ with a range between $0.35 \%$ and $0.6 \%$ which is a large range as compared to mode 2 . 


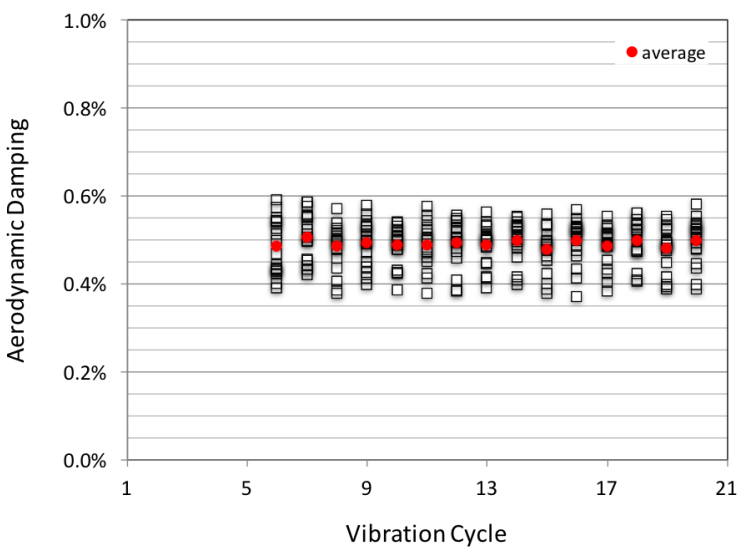

Figure 21. Mode 3, 1 ND aerodynamic damping with BLI distorted inflow.

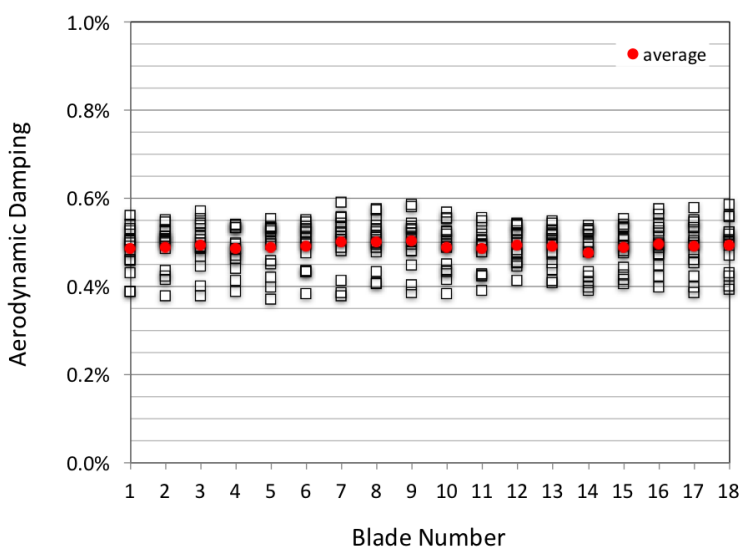

Figure 22. Mode 3, 1 ND aerodynamic damping with BLI distorted inflow for each blade.

The computations with BLI distortion and blade vibration are repeated at the $85 \%$ and $70 \%$ rotational speed for the first three vibration modes. The detailed results are not presented here but all the results over a matrix of 3 rotational speeds, 3 modes, and 3 nodal diameter patterns are summarized in Table 2. The aerodynamic damping is seen to be the lowest for mode 2 for the 1 nodal diameter pattern (forward-traveling wave). But, for all the conditions analyzed, the aerodynamic damping values are positive indicating no flutter.

Table 2. Summary of aerodynamic damping for DTF fan.

\begin{tabular}{cccccccccc}
\hline & \multicolumn{3}{c}{$100 \%$ speed } & \multicolumn{3}{c}{$85 \%$ speed } & \multicolumn{3}{c}{$70 \%$ speed } \\
Mode & $-1 \mathrm{ND}$ & $0 \mathrm{ND}$ & $+1 \mathrm{ND}$ & $-1 \mathrm{ND}$ & $0 \mathrm{ND}$ & $+1 \mathrm{ND}$ & $-1 \mathrm{ND}$ & $0 \mathrm{ND}$ & $+1 \mathrm{ND}$ \\
\hline 1 & $0.8 \%$ & $0.5 \%$ & $0.8 \%$ & $>0.9 \%$ & $0.8 \%$ & $>0.9 \%$ & $>0.7 \%$ & $>0.8 \%$ & $>0.9 \%$ \\
\hline 2 & $>0.2 \%$ & $0.5 \%$ & $0.2 \%$ & $0.2 \%$ & $0.4 \%$ & $0.2 \%$ & $0.3 \%$ & $0.5 \%$ & $0.2 \%$ \\
\hline 3 & $0.7 \%$ & $0.7 \%$ & $0.4 \%$ & $0.7 \%$ & $0.7 \%$ & $0.5 \%$ & $0.5 \%$ & $0.7 \%$ & $0.5 \%$ \\
\hline
\end{tabular}

Since flutter can sometimes occur at part-speed conditions near the stall line (or stability limit line), analysis is done for the $70 \%$ rotational speed near the stall line. The analysis results summarized in Table 3 show that the mode 2 damping does decrease but remains positive. The lowest values of aerodynamic damping calculated were $0.1 \%$ and indicated the need to monitor the blade vibrations carefully during the wind tunnel test. Also, results of analysis done on the choke side at $100 \%$ speed (Table 4 ) indicated no flutter.

Table 3. Aerodynamic damping at $70 \%$ speed near stall line for DTF fan.

\begin{tabular}{cccc}
\hline & \multicolumn{3}{c}{$70 \%$ speed (near stall) } \\
Mode & $-1 \mathrm{ND}$ & $0 \mathrm{ND}$ & $+1 \mathrm{ND}$ \\
\hline 1 & $>0.4 \%$ & $0.6 \%$ & $>0.3 \%$ \\
\hline 2 & $0.2 \%$ & $0.1 \%$ & $0.1 \%$ \\
\hline 3 & $0.3 \%$ & $0.7 \%$ & $0.25 \%$ \\
\hline
\end{tabular}

Table 4. Aerodynamic damping at $100 \%$ speed near choke for DTF fan.

\begin{tabular}{c|ccc}
\hline & \multicolumn{3}{|c}{$100 \%$ speed (near choke) } \\
Mode & $-1 \mathrm{ND}$ & $0 \mathrm{ND}$ & $+1 \mathrm{ND}$ \\
\hline 1 & $0.8 \%$ & $0.5 \%$ & $0.8 \%$ \\
\hline 2 & $0.3 \%$ & $0.5 \%$ & $0.3 \%$ \\
\hline 3 & $0.4 \%$ & $0.7 \%$ & $0.4 \%$ \\
\hline
\end{tabular}


All the computations performed showed no flutter with very low levels of aerodynamic damping at some conditions. Based on these results, the wind tunnel test proceeded with monitoring of strain gages and non-contacting optical casing probes. During the test, flutter was encountered at only one condition $-100 \%$ rotational speed near the stall line. No computational analysis was done at the operating condition where flutter was observed during the test because stable converged flow solutions could not be obtained for that low of a mass flow rate at $100 \%$ speed. In essence, the flutter was observed beyond the numerical stability limit line. Further work is required to understand how flutter computations can be performed near the operating conditions where flutter occurred during the test. In addition, the observed structural mode ${ }^{21,22}$ during flutter was mode 1 and a 2 ND pattern was identified through post-test data analysis. In contrast, the TURBO computations showed the lowest levels of aerodynamic damping for mode 2 and a $1 \mathrm{ND}$ pattern. However, the TURBO results do show the largest decrease in the aerodynamic damping from the nominal operating point to near stall occurs for the 2 ND pattern (Figs. 11 and 12).

\section{Fan Blade Resonant Response}

The BLI distortion produces periodic unsteady aerodynamic excitations on the DTF fan. When one of these periodic excitations has a frequency close to a natural frequency of the fan blades, there is a potential for a large resonant response. The fan blades and disk are designed to avoid responses to known resonant excitations at design rotational speed by providing adequate margin between the excitation frequencies and the natural frequencies. However, the excitation frequencies are harmonics of the rotational frequency and therefore increase linearly with the fan rotational speed. The natural frequencies of the fan blades change somewhat due to various levels of centrifugal stiffening and softening, depending on the mode. Consequently, frequency crossings between excitation frequencies (engine orders) and natural frequencies are typically present at some part-speed operating conditions that can lead to resonant response of the fan blades. During the wind tunnel test, forced response dynamic stresses and blade tip vibrations were measured at select resonant crossings for the DTF fan. A specific resonant response is analyzed here.

The modal forced response analysis method, described in Ref. 10, is used in the present work to calculate resonant response. The fan blade forced response near a resonance is dominated by a single mode unless the modes are closely spaced. Since the lower modes of the DTF fan blade are well separated from each other ${ }^{20-22}$, it is not necessary to include other modes in the resonant response analysis. Further, the BLI distortion produces aerodynamic excitations that act as (backward) traveling waves on the fan blades and excite only specific blade modes with particular nodal diameter patterns when the dynamics of blade to blade differences in structural characteristics (mistuning) is not included in the formulation. For example, the 4th harmonic of the excitation on the DTF fan from the BLI distortion unsteadiness, referred to as engine order 4 (4E or 4EO) excites only the $4 \mathrm{ND}$ (nodal diameter) pattern mode of the DTF fan. At around $85 \%$ speed, the frequency of the 4EO excitation matches the natural frequency of the 4 nodal diameter pattern of mode 2 . This is the specific resonant response analyzed in detail here.

The BLI distortion generates an unsteady flowfield in the DTF fan and results in an unsteady pressure variation on the fan blades. The modal force on the fan blades is calculated from the TURBO unsteady pressure distribution, blade geometric area and blade modal displacement. In this case, the 4th harmonic of the unsteady pressure is used along with the modal displacements for 4ND of mode 2 to calculate the modal force. As noted in Refs. 10 and 23, the 4EO or 4th harmonic component of excitation is likely to be small as compared to the first three engine order excitations. This resonant crossing is examined here because the rotational speed is close to the design speed and the unsteady flowfield is expected to be modeled with reasonable accuracy.

At $85 \%$ rotational speed, the natural frequency calculated from the modal analysis is $679.5 \mathrm{~Hz}$ for mode 2 for the $4 \mathrm{ND}$ pattern. For the resonant response calculation, the excitation frequency is set equal to the natural frequency. The TURBO solution from $85 \%$ speed and $95.8 \mathrm{lb} / \mathrm{s}$ corrected flow rate is used to calculate the modal force. A total damping of $1 \%$ is assumed for the analysis. The resonant response displacement amplitude is calculated at the blade tip location approximately 0.125 inches downstream of the blade leading edge. This location corresponds to the tip probe location of the optical measurement system in the wind tunnel test, as described in Ref. 22. The calculated response amplitude is 16.2 mils. To provide a measure of the variation along the blade tip, the response at the leading edge tip location ( 0.125 mils upstream) is calculated to be 17.3 mils.

During the wind tunnel test, data was acquired ${ }^{21-22}$ at this resonant crossing for aeromechanics code validation by increasing the fan rotational speed at a constant rate through this crossing. Analysis of the data provides the following information at resonance for each of 18 blades as measured by each of 7 probes: rotational speed, vibration frequency, response amplitude, and damping. The measurements were acquired in three separate test runs at approximately the same nominal test and operating conditions. The analysis results are compared to all these measured values ${ }^{22}$ in Fig. 23. The average resonant frequency measured for all blades by 7 optical probes is $678.4 \mathrm{~Hz}$, the average damping 
measured is $1.09 \%$, and the average response amplitude is 27.6 mils. The measured response varies from 13 to 46 mils and the measured damping varies from $0.7 \%$ to $1.9 \%$. In addition to the analysis with an assumed damping of $1 \%$, the response amplitudes are also calculated with the measured damping values. The calculated response is seen to be lower than most of the measured responses. The comparisons indicate that the forcing function or unsteady aerodynamic excitation is under-predicted.

A closer examination of the unsteady flowfield calculated using the TURBO code shows that some non-periodic characteristics are present that result in a variation of the 4EO excitation across all the blades. Figure 24 shows the variation of the normalized modal force (magnitude) for the 4EO excitation, indicating that the average excitation is about $7 \%$ higher than the baseline value used in this analysis. Thus, the calculated response may be higher than the value plotted in Fig. 23 by a similar percentage based on the linear relationship between forcing function and response. Similarly, Fig. 25 shows that the variation of the phase difference of the modal force (between adjacent blades) varies about \pm 10 degrees around the expected value of 80 degrees for the 4 th harmonic.

Additional analyses were performed to examine the sensitivity of the 4EO excitation to operating conditions. Figure 26 shows the variation with fan mass flow rate of the normalized modal force (magnitude) on a selected blade for the $4 \mathrm{EO}$ excitation. The results indicate that the magnitude of the $4 \mathrm{EO}$ modal force changes by $5-6 \%$ with a $1 \mathrm{lb} / \mathrm{s}$ change in mass flow rate. Additional TURBO analyses are required to examine the sensitivity of the unsteady loading to other operating conditions such as fan rotational speed. A possible improvement in the analysis will be to extend computations to a coupled inlet-fan domain, which would allow a more realistic and accurate interaction between the fan and the BLI distortion. Another possible improvement will be to include blade to blade variations in structural properties (mistuning) to examine if the effects are significant for this blade-disk configuration.

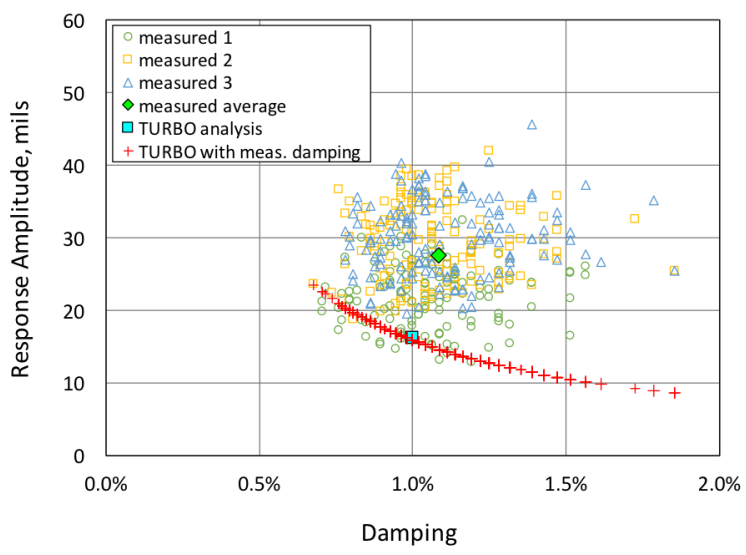

Figure 23. Resonant response at $85 \%$ rotational speed for $4 \mathrm{EO}$ mode 2 .

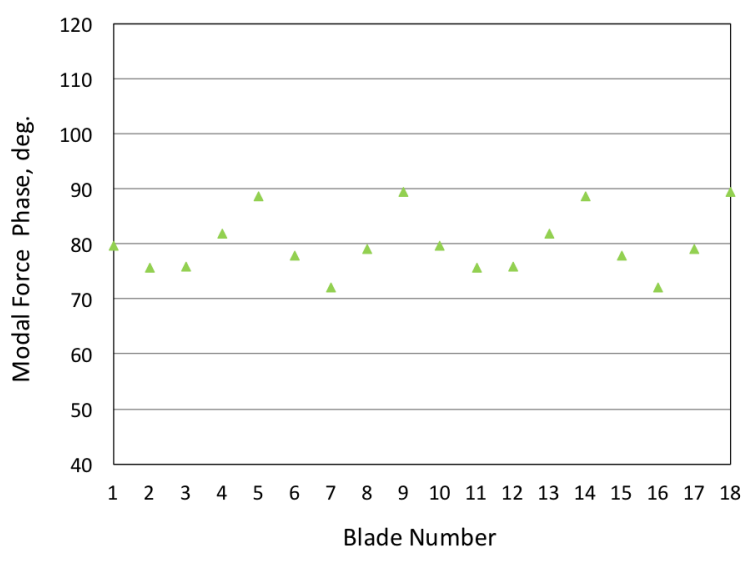

Figure 25. Variation of the phase of 4EO modal force across all blades.

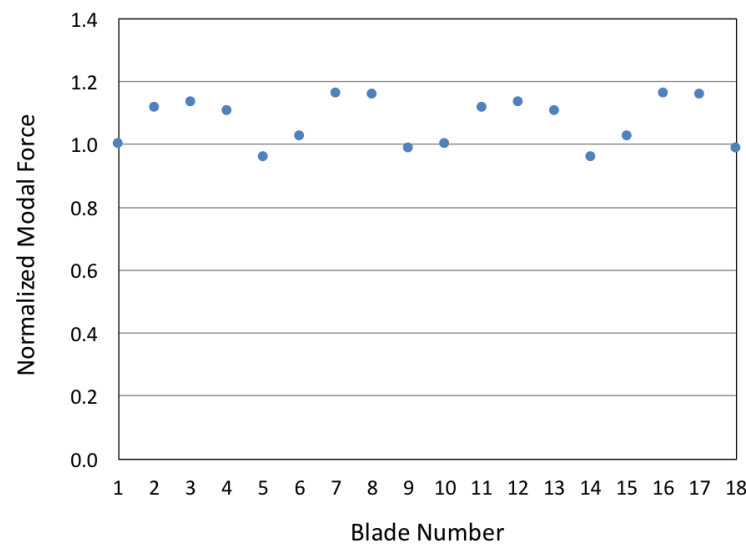

Figure 24. Variation of normalized 4EO modal force (magnitude) across all blades.

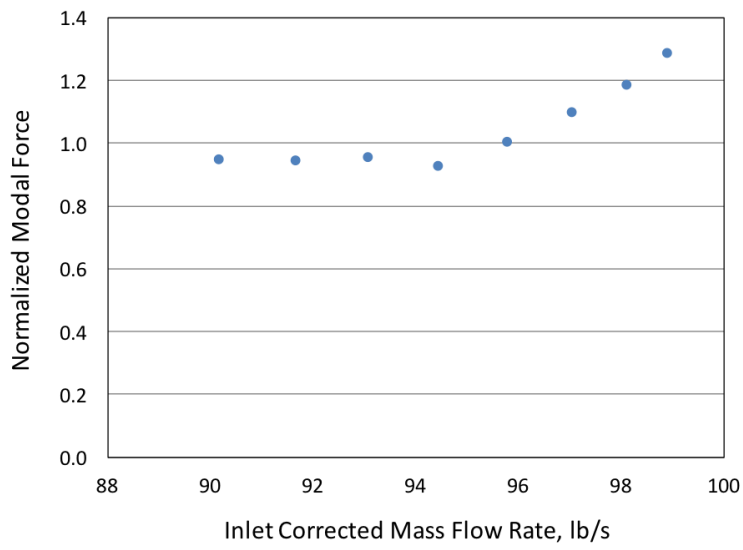

Figure 26. Variation of normalized 4EO modal force (magnitude) with mass flow rate. 


\section{Concluding Remarks}

A successful application of Boundary Layer Ingestion (BLI) propulsion will require that the fan must have acceptable aeromechanical characteristics to operate in a persistent inlet distortion generated by the BLI inlet. Also, the fan aerodynamic performance must not be decreased significantly or the expected fuel burn reduction will not be realized. Accurate aeromechanics analyses can be used in the design to ensure that the fan will have satisfactory aeromechanical characteristics to meet the design requirements to operate continuously with boundary layer ingestion.

In this study, the aeromechanical characteristics of a distortion-tolerant fan have been analyzed in the presence of a BLI distortion. Only the fan rotor was modeled as part of this study and the inlet flow distortion due to ingestion of the boundary layer was imposed as the inflow boundary condition for the fan analysis. A structural model was developed from the blade and disk geometries to provide accurate structural dynamics characteristics required for the aeromechanical analyses: mode shapes, frequencies, and modal stresses. The unsteady aerodynamic model was based on the time-domain solution of the Reynolds-averaged Navier Stokes equations. Flutter analyses were based on the energy method, or work-per-cycle method, with prescribed blade vibrations to calculate the aerodynamic damping.

Baseline fan flutter analyses were first performed using inflow conditions that consist of only radial variations of flow quantities. The BLI distortion was circumferentially averaged to obtain these radial profiles. The first three vibration modes were analyzed at three fan rotational speeds and operating conditions near a typical nominal operating line and near the numerical stability limit or towards the stall line. The aerodynamic damping was seen to drop to very low values for low nodal diameter patterns. However, the aerodynamic damping remained positive at all conditions that were analyzed, indicating no flutter. Sensitivity of the analysis to numerical parameters such as time step and amplitude scale factor did not reveal any unexpected characteristics.

To examine flutter stability in the presence of the BLI distortion, analyses were done with both the inlet distortion and blade vibrations simultaneously modeled. The energy method was used and the work done on the blade by the unsteady pressure due to blade vibration was separated out to calculate the aerodynamic damping. No flutter was encountered in the number of cases examined for the first three vibration modes near the nominal operating line at three rotational speeds: $100 \%, 85 \%$, and $70 \%$. Additionally, analyses at $70 \%$ rotational speed near stall and at $100 \%$ rotational speed near choke did not show flutter. The nodal diameter patterns selected for analysis were those for which the aerodynamic damping was near a minimum in the circumferentially-averaged inflow analyses.

Some near-stall analysis results showed very large scatter in the calculated aerodynamic damping, which indicated that the approach used to separate out the unsteady pressure due to blade vibration did not work correctly at these conditions. A possible reason may be large levels of non-periodic unsteadiness at these conditions that significantly changed in the presence of blade vibrations. A different approach such as a two-way coupled time domain analysis may be needed to examine flutter stability for these conditions. A two-way coupled aeroelastic analysis, in which the blade vibrations and unsteady flow are closely coupled in both directions, may provide a more detailed and accurate representation of the interactions between the unsteady flow due to inlet distortion and blade vibrations and the resulting effects on flutter stability and forced response. This analysis is planned to be done in the future. In addition, future work with a coupled inlet-fan domain will allow a more realistic and accurate modeling of the interaction between the fan and the BLI distortion. A coupled inlet-fan analysis will also allow the inflow boundary to be moved away from the fan rotor and thus alleviate any numerical difficulties associated with prescribing an inflow distortion profile very near the fan.

The flutter analyses performed in this work showed low positive levels of aerodynamic damping at various conditions analyzed. These analysis results are consistent with the observations in the wind tunnel test in which no flutter was encountered, except at one condition. However, this condition could not be analyzed since it fell beyond the numerical stall line where converged flow solutions could not be obtained.

To examine the resonant response at part-speed conditions, analysis was done near $85 \%$ rotational speed where the 4 th engine order excitations excite the 4 th nodal diameter pattern of blade mode 2 . The modal analysis method was used to calculate the resonant response amplitude. The response was compared to blade tip vibration measurements from the wind tunnel test and the response amplitude was found to be under-predicted for this resonant crossing. The frequency of the expected crossing was well predicted based on the structural analysis. The relatively small excitation and response levels are considered to be factors in the under-prediction of the response since it is difficult to accurately predict the smaller unsteady pressure variations. In addition, the BLI distortion prescribed at the inflow boundary needs to be examined to ensure that it accurately represents the measurements - this work is planned for the future. As mentioned earlier, the extension of the domain to include the inlet along with the fan would enable a more realistic analysis of the interactions between the BLI inlet distortion and the fan. Further analysis is required to examine the resonant response at lower rotational speeds where the 2nd and 3rd engine order excitations lead to large resonant responses for the first blade mode. These large responses provide much cleaner measured data above 
the noise levels and general unsteadiness. One difficulty in modeling these conditions is that BLI distortion profiles are not currently available for these low rotational speeds and would have to be generated using separate flow analyses or acquired in a future wind tunnel test.

\section{Acknowledgments}

The authors gratefully acknowledge the support of this work provided by the Advanced Air Transport Technology Project (Dr. James Heidmann, Project Manager and Mr. Christopher Hughes Sub-Project Manager). The authors would like to acknowledge Mr. David Arend for his leadership of the BLI2DTF task. The authors would like to acknowledge Mr. Timothy Beach for generating the meshes required for all the TURBO analyses. Computational resources supporting this work were provided by the NASA High-End Computing (HEC) Program through the NASA Advanced Supercomputing (NAS) Division at Ames Research Center.

\section{References}

${ }^{1}$ Smith, L. H., "Wake Ingestion Propulsion Benefit," AIAA Journal of Propulsion and Power, Vol. 9, No. 1, Jan.-Feb., 1993, pp. $74-82$

${ }^{2}$ Daggett, D., Kawai, R., and Friedman, D., "Blended Wing Body Systems Studies: Boundary Layer Ingestion Inlets with Active Flow Control," NASA/CR-2003-212670, December 2003.

${ }^{3}$ Kawai, R., Friedman, D., and Serrano, L., "Blended Wing Body (BWB) Boundary Layer Ingestion (BLI) Inlet Configuration and Systems Studies," NASA/CR-2006-214534, December 2006.

${ }^{4}$ Plas, A. P., Sargeant, M. A., Madani, V., Crichton, D., Greitzer, E. M., Hynes, T. P., and Hall, C. A., "Performance of a Boundary Layer Ingesting (BLI) Propulsion System," AIAA Paper 2007-0450, January 2007.

${ }^{5}$ Nickol, C. L., and McCullers, L. A., "Hybrid Wing Body Configuration System Studies,” AIAA-2009-931, January 2009.

${ }^{6}$ Tillman, T. G., Hardin, L. W., Moffitt, B. A., Sharma, O. P., Lord, W. K., Berton, J., and Arend, D., "System-Level Benefits of Boundary Layer Ingesting Propulsion," invited presentation, AIAA 49th Aerospace Sciences Meeting, January 2011.

${ }^{7}$ Hardin, L. W., Tillman, T. G., Sharma, O. P., Berton, J. J., and Arend, D. J., "Aircraft System Study of Boundary Layer Ingesting Propulsion,” AIAA Paper 2012-3993, July-August 2012.

${ }^{8}$ Ochs, S. S., Tillman, G., Joo, J., and Voytovych, D. M., "Computational Fluid Dynamics-Based Analysis of Boundary Layer Ingesting Propulsion", AIAA Journal of Propulsion and Power, Vol. 33, No. 2, March-April, 2017, pp 522-530.

${ }^{9}$ Arend, D. J., Wolter, J. D., Hirt, S. M., Provenza, A. J., Gazzaniga, J. A., Cousins, W. T., Hardin, L. W., Sharma, O. P., "Experimental Evaluation of an Embedded Boundary Layer Ingesting Propulsor for Highly Efficient Subsonic Cruise Aircraft," AIAA Paper 2017-5041, July 2017.

${ }^{10}$ Bakhle, M. A., Reddy, T. S. R., Herrick, G. P., Shabbir, A, and Florea, R. V., “Aeromechanics Analysis of a Boundary Layer Ingesting Fan," AIAA Paper 2012-3995, July 2012.

${ }^{11}$ Giuliani, J. E., Chen, J. P., Beach, T. A., and Bakhle, M. A., "Numerical Simulation of Boundary Layer Ingesting (BLI) Inlet/Fan Interaction,” AIAA Paper 2014-3731, July 2014.

${ }^{12}$ Chen, J.-P., and Whitfield, D. L., "Navier-Stokes Calculations for the Unsteady Flowfield of Turbomachinery," AIAA Paper 1990-0676, January 1990.

${ }^{13}$ Chen, J.-P. and Briley, W. R., “A Parallel Flow Solver for Unsteady Multiple Blade Row Turbomachinery Simulations,” ASME Paper GT2001-0348, June 2001.

${ }^{14}$ Srivastava, R., Bakhle, M. A., and Keith, T. G., Jr., "Numerical Simulation of Aerodynamic Damping for Flutter Analysis of Turbomachinery Blade Rows," AIAA Journal of Propulsion and Power, Vol. 19, No. 2, March 2003.

${ }^{15}$ Srivastava, R., Bakhle, M. A., Keith, T. G., Jr., and Stefko, G. L., "Flutter Analysis of a Transonic Fan," ASME Paper GT2002-30319, June 2002.

${ }^{16}$ Bakhle, M. A., Liu, J. S., Panovsky, J., Keith, T. G. Jr., and Mehmed, O., "Calculation and Correlation of the Unsteady Flowfield in a High Pressure Turbine,” ASME Paper GT-2002-30322, June 2002.

${ }^{17}$ Herrick, G. P., "Effects of Inlet Distortion on Aeromechanical Stability of a Forward-Swept High-Speed Fan," AIAA Paper 2010-6711, August 2010.

${ }^{18}$ Carta, F. O., "Coupled Blade-Disk-Shroud Flutter Instabilities in Turbojet Engine Rotors," Trans ASME Journal of Engineering for Power, Vol. 89, No.3, pp. 419- 426, July 1967.

${ }^{19}$ Bakhle, M. A., Reddy, T. S. R., and Stefko, G. L., "Comparisons of Flutter Analyses for an Experimental Fan," NASA/TM2010-216221, Apr. 2010.

${ }^{20}$ Min, J. B., Reddy, T. S. R., Bakhle, M. A., Coroneos, R. M., Stefko, G. L., Provenza, A. J., and Duffy, K. P., "Cyclic Symmetry Finite Element Forced Response Analysis of a Distortion-Tolerant Fan with Boundary Layer Ingestion," AIAA SciTech Forum, January 2018 (submitted for publication).

${ }^{21}$ Provenza, A. J., Duffy, K. P., and Bakhle, M. A. "Aeromechanical Response of a Distortion-Tolerant Boundary Layer Ingesting Fan,” ASME Turbo Expo, June 2018 (submitted for publication). 
${ }^{22}$ Duffy, K. P., Provenza, A. J., Bakhle, M. A., Min, J. B., and Abdul-Aziz, A., "Laser Displacement Measurements of Fan Blades in Resonance and Flutter During the Boundary Layer Ingesting Inlet and Distortion-Tolerant Fan Test," AIAA SciTech Forum, January 2018 (submitted for publication).

${ }^{23}$ Bakhle, M. A., Reddy, T. S. R., and Coroneos, R. M., "Forced Response Analysis of a Boundary Layer Ingesting Fan," AIAA Paper 2014-3734, July 2014. 